\title{
What Moderates the Too-Much-Choice Effect?
}

\author{
Benjamin Scheibehenne \\ Max Planck Institute for Human Development and Indiana University \\ Rainer Greifeneder \\ University of Mannheim \\ Peter M. Todd \\ Indiana University
}

\begin{abstract}
Core theories in economics, psychology, and marketing suggest that decision makers benefit from having more choice. In contrast, according to the too-much-choice effect, having too many options to choose from may ultimately decrease the motivation to choose and the satisfaction with the chosen option. To reconcile these two positions, we tested whether there are specific conditions in which the too-much-choice effect is more or less likely to occur. In three studies with a total of 598 participants, we systematically investigated the moderating impact of choice set sizes, option attractiveness, and whether participants had to justify their choices. We also tested the moderating role of search behavior, domain-specific expertise, and participants' tendency to maximize, in a within-subject design. Overall, only choice justification proved to be an effective moderator, calling the extent of the too-much-choice effect into question. We provide a theoretical account for our findings and discuss possible pathways for future research. @ 2009 Wiley Periodicals, Inc.
\end{abstract}

Suppose you are on vacation in Berlin and you wish to dine at a nice restaurant. To make your choice easier, you consult a local restaurant guidebook. Opening the guidebook, you face a stunning number of more than 1200 restaurants you 
could go to. Overwhelmed? Maybe your easiest option is just to defer choice or go to a default fast-food option and donate the money you save to charity instead. But again, this next choice might also prove very difficult. If you go online and search for a charity with charitynavigator.com, you will confront a list of hundreds of organizations worthy of your money. Beyond the fact that making an informed choice from such a long list can be daunting, even if you do choose a particular organization, you will end up giving nothing to many other organizations with similarly noble goals, which could also engender feelings of dissatisfaction.

As these two examples illustrate, having many options to choose from might not always be a blessing. In particular, recent empirical findings suggest that an overly large number of options can lead to negative consequences. Large assortments, as compared to small ones, have been found to foster dissatisfaction, regret, disappointment, decreased motivation to make a choice, or decreased consumption rates, all of which are manifestations of what has been termed the too-much-choice effect, choice overload, or hyperchoice (Botti \& Iyengar, 2006; Chernev, 2003b; Iyengar \& Lepper, 2000; Iyengar, Jiang, \& Huberman, 2004; Reutskaja \& Hogarth, 2009; Shah \& Wolford, 2007; Haynes, 2009). Are people doomed to suffer negative consequences of ever-increasing choice in our modern world?

Recent research suggests that this is so. In a seminal paper by Iyengar and Lepper (2000), participants who were presented with a large assortment were less motivated to make a choice or less satisfied with their chosen alternative. In a field study conducted at an upscale grocery store in the United States, the researchers found that $30 \%$ of all consumers who sampled a small assortment consisting of six exotic jams at a tasting display actually purchased one of the jams (with a coupon), while in a comparison group that could taste from a large assortment of 24 exotic jams of the same brand, only $3 \%$ of the customers bought one. In another study, Iyengar and Lepper let two groups of participants choose one piece out of an array of Godiva chocolates. One group chose among 30 different Godiva chocolates (large assortment size); the other group chose among 6 different chocolates (small assortment size). In this case, participants who chose from the large assortment reported higher enjoyment of the decision than participants who chose from the small assortment. But at the same time, the former participants reported greater difficulty and more frustration in making the decision and less satisfaction with the praline they finally chose. They were also less likely to accept a box of Godiva chocolate instead of money as compensation for their participation ( $12 \%$ vs. $48 \%$ in the small assortment condition). In a third study, Iyengar and Lepper found a demotivating too-much-choice effect for participants choosing essay topics to write about.

Following this work, Iyengar, Jiang, and Huberman (2004) found that the more options participants could choose from for a retirement plan, the longer they delayed their choice, ultimately forgoing considerable financial benefits. Reutskaja and Hogarth (2009) found that individuals' satisfaction with a simulated gift box decreased with the number of gift boxes to choose from, and Haynes (2009) found similar results for choices among lottery prices. Likewise, Shah and Wolford (2007) reported that the percentage of participants who were motivated to purchase a black pen decreased from $70 \%$ when choosing from small assortments (8 to 14 pens) to $33 \%$ when choosing from large assortments (16 to 20 pens).

Taken together, this empirical evidence supports the idea that an overly large assortment can have negative consequences. But such results are surprising, 
because this effect contradicts many theories in the fields of economics, psychology, marketing, and management science, according to which a wider proliferation of choice cannot make decision makers worse off but rather entails a number of advantages. For example, having options to choose from is often seen as an important prerequisite of personal freedom: Choice allows individuals to live their lives according to their own agendas (Schwartz, 2004). Having more options to choose from also reduces the costs of searching options and allows for an easier comparison among them (Hutchinson, 2005). Furthermore, evidence shows that consumers relish choice and prefer large assortments over smaller ones, and stores that offer a large variety have a competitive advantage over those that offer less, which is paradoxical from the vantage point of choice overload (Arnold, Oum, \& Tigert, 1983; Brown, Read, \& Summers, 2003; Craig, Gosh, \& McLafferty, 1984; Hutchinson, 2005; Kahn, 1995; Mazursky \& Jacoby, 1986; Koelemeijer \& Oppewal, 1999; Chernev, 2003a). Moreover, Kahn and Wansink (2004) showed in a series of experiments that children as well as adults eat more candies if they perceive the variety of the candy assortment as being high.

In sum, there are opposing views on whether having many choices is associated with positive or negative consequences. One way to reconcile these views is to search for variables that moderate an effect of too much choice. In this article we aim to do just that, seeking a better understanding of the conditions and underlying mechanisms that can explain when and why an increase in the number of options leads to negative consequences. In three studies, we analyze specific moderators that have either been proposed by other researchers or are derived from past research on choice. In the first study (restaurants), we test whether the too-much-choice effect is driven by the mean attractiveness of the small compared to the large assortment, and by individual differences in the subjective perception of variety of each assortment. In the second study (charities), we extend our analysis of the assortment structure by further varying the number of options to choose from. In addition, we test whether the effect is influenced by the need to justify any choice one makes, and we explore the moderating role of preferences prior to choice. The second study also tests for cultural differences in the prevalence of the effect. Study 3 (music) refines the previous tests for cultural differences and for subjective perceptions of the assortment in a within-subject design, and also explores the moderating role of individual differences in the propensity to search, to maximize, and to regret one's outcomes. Together, these theoretical and empirical analyses help us to improve the picture of how psychological mechanisms interact with environment structure to sometimes produce the too-much-choice effect, and suggest further routes to explore to fill in more of this picture.

\section{THE RESTAURANT STUDY}

The first study tests the moderating influence of a decision maker's subjective perception of the variety. Kahn and Wansink (2004) found that it is the perception of variety rather than the mere number of options that ultimately determines consumption quantity. Similarly, Broniarczyk, Hoyer, and McAllister (1998) found that the perception of variety available in a store does not depend solely on the mere number of different options but also on other aspects including a consumer's prior expectations and experiences, as well as how much physical 
space an assortment takes up on a display shelf. In line with this, Huffman and Kahn (1998) argued that perceptions of variety can be influenced by an individual's perceptual selectivity: For example, within his or her field of expertise, an expert can process more options than a layperson, and hence will be less likely to perceive a given assortment as containing too much variety (Chase \& Simon, 1973). Thus, to the degree that the perception of assortment size differs among individual decision makers, an effect of choice overload would only be expected for participants who subjectively perceive the assortment as large.

For this study (as for the other two that follow), we chose stimuli that would not be too familiar to our participants-in this case, a range of restaurants in Berlin. This is in keeping with the earlier studies outlined above that found the too-much-choice effect, all of which were designed so that participants would not have well-defined prior preferences. For example, in the Iyengar and Lepper jam study (2000, Experiment 1), the researchers purposely used an exotic brand of jam that most participants were not familiar with. Previous research suggests that this lack of clear goals or preferences prior to choice might moderate the too-much-choice effect because individuals with clearly defined preferences prior to choice are more willing to make a choice and experience greater satisfaction with the chosen alternative, provided that their preferences can be matched (Huffman \& Kahn, 1998). Furthermore, the probability that these prior preferences can indeed be matched rises with the number of available options, leading to the opposite, more-is-better effect for decision makers with well-defined prior preferences (Kahn, 1995; Chernev, 2003b; Broniarczyk, Hoyer, \& McAllister, 1998). Thus, by also using unfamiliar options in our experiments, we set up a starting condition where the too-much-choice effect is most likely to occur.

\section{Method}

Participants were invited to the lab and asked to browse through a list of restaurants described on several attributes. Participants were then entered into a lottery with a 1-in-40 chance to win. Participants had to choose what they would want to receive if they won the lottery: either 30 euros in cash (approximately $\$ 36$ at that time) or a restaurant coupon worth 40 euros (approximately $\$ 48$ ). If they chose the coupon, they had to pick one restaurant from the list, for which the coupon would be issued. Participants were told about this subsequent choice before they made their cash/coupon choice. The percentage of participants choosing the restaurant coupon over the cash was the main dependent variable, while number of restaurants in the list was the main independent variable.

Stimuli. In the large assortment condition, 30 restaurants were presented, spread equally over the following five cuisines: Italian, Asian, German, French, and International. The small choice set consisted of 5 restaurants, one of each cuisine type.

The restaurant descriptions were taken from a recent restaurant guide for the city of Berlin (Marcellino's Restaurant Report). The average price for a main dish in all restaurants used ranged between 10 and 20 euros (approximately $\$ 12$ to $\$ 24$ ). Only restaurants in the center of Berlin were selected. As Marcellino's Restaurant Report often listed more than six restaurants per cuisine type for this region, restaurants were chosen to ensure an equal distribution of food prices between the different cuisines. 
Each restaurant was described on a small sheet of paper using a short narrative description and a numerical rating for the quality of food, drinks, service, and atmosphere, all taken from the restaurant guide. The participants were also told the name, address, and type of cuisine for each restaurant. The descriptions were assembled in booklets in two different random orders, together with a cover sheet saying "Restaurant Descriptions."

To further increase our chances of finding the effect, we ran the large choice condition first to find out which restaurants were chosen most often by our participants (and thus were most attractive). The small choice set was then constructed from the most attractive restaurant for each cuisine. Thus, it had a total of five attractive restaurants to choose from, which increased the average attractiveness of the small set as well as the probability of finding a good option within this set.

Perceived Variety and Control Measures. To measure perceived variety, participants were asked to judge the assortment of the offered restaurants on a Likert scale ranging from 1 ("very little variety") to 7 ("very much variety"). The middle of the scale was described as "average variety." Participants who preferred a restaurant coupon over a cash coupon were also asked how difficult it was to make a choice, on a scale from 1 ("very easy") to 7 ("very difficult"). As we used descriptions of real restaurants, we controlled for potential prior preferences by asking participants whether they knew each restaurant and, if so, whether they had eaten there before. To control for the possibility that the attractiveness of the restaurant coupon decreased the further participants lived away from the center of Berlin, participants were asked in which part of the city they lived and in which part they worked or studied.

Participants. In total, 80 students from local universities participated, 40 in each choice-set size condition. The average age was 25 years, ranging from 19 to 33 years, with no significant differences between the two experimental conditions. Within both conditions, half of the participants were male and half were female.

\section{Results}

Manipulation Checks. Participants in the large-choice condition had never heard of $80 \%$ of the restaurants on average (24 out of 30; SD =4.2) and had never eaten at $95 \%$ of the restaurants $(28.5$ out of $30 ; \mathrm{SD}=2.9)$. Participants in the small-choice condition had never heard of $75 \%$ of the restaurants (3.7 out of 5 ; $\mathrm{SD}=1.2)$ and had never eaten at $86 \%$ of the restaurants $(4.3$ out of $5 ; \mathrm{SD}=0.8)$. The percentage of recognized restaurants (the familiarity with the choice set) was not related to the probability of choosing a restaurant coupon $(r=0.01$, $p=0.98)$, nor to the perceived assortment size $(r=-0.22, p=0.5)$.

Effect of Assortment Size. The variety of the large assortment was perceived as rather high $(M=4.9$ on a scale from 1 to 7 ; SD $=1.4)$ and higher than the size of the small assortment $(M=3.1, \mathrm{SD}=1.5)[t(78)=5.61 ; p<0.01]$. Participants who chose a restaurant from the large assortment reported slightly more difficulty in making a choice $(M=3.2, \mathrm{SD}=1.6$ vs. $M=2.4, \mathrm{SD}=1.4$ in the small assortment) $[t(23)=1.9 ; p=0.066]$. Yet for the main dependent 
variable, the number of participants who preferred a restaurant coupon over a cash coupon, there was hardly any difference between the large and the small choice set: From the large set, 14 out of 40 participants (35\%) chose a restaurant coupon, while from the small set, 12 out of 40 (30\%) chose a restaurant coupon. Thus, if anything, participants were more likely to choose from the large assortment even though the average attractiveness of the options presumably was higher in the small set.

The perception of variety was unrelated to the probability of choosing one of the restaurants in the large condition $(r=0.16, p=0.346)$ and also across both conditions ( $r=0.17, p=0.360$ ). Thus, contrary to our hypothesis, the subjective perception of variety did not seem to moderate individuals' choice propensity.

\section{Discussion}

The results of Study 1 show no evidence of the too-much-choice effect. In contrast to the idea of choice overload, participants were equally likely to choose a restaurant coupon regardless of whether they had made a choice out of a small or large set. What might distinguish our experiment from those in which an effect was found? As in previous experiments with unfamiliar options, the restaurants we used were mostly unknown to our participants, and familiarity with the choice set did not influence the effect. Nevertheless, choosing a restaurant is not uncommon in daily life and therefore participants might still have had specific prior preferences for types of restaurants or cuisines. Also, it could be that the lottery we included at the end of our study introduced an additional source of error due to individual differences in risk-taking behavior. Finally, there is no clear-cut definition of what constitutes too much choice, and as a consequence it could be that 5 different options in the small set were already sufficient to induce choice overload, or that 30 different restaurants were not enough. To rule out these explanations, and in order to test other potential moderators, the next study used three experiments involving concrete choices among a wider range of options that are less common in everyday life, namely, public charity organizations.

\section{THE CHARITY STUDY}

The next series of three experiments aims to explicitly test the influences of five potential moderating variables, namely, well-defined preferences held prior to choice (Experiment 2a), cultural differences (Experiment 2b), further increases in assortment sizes (Experiments $2 \mathrm{~b}$ and $2 \mathrm{c}$ ), and choice justification (Experiment 2c). Participants in all three experiments had to decide whether to donate a certain amount of money to a charity organization or keep the money for themselves. The number of charity organizations to choose from was subject to experimental manipulation, and the percentage of participants who gave the money to charity was the main dependent variable.

\section{Experiment 2a: Prior Preferences as a Moderator}

In contrast to the selection of a restaurant, choices among different charity organizations are much less common. To further control for the moderating 
effect of clear preferences prior to choice, the level of publicity of the presented charity organizations was experimentally manipulated by constructing one pair of choice sets consisting of large and presumably well-known organizations, and another pair consisting of very small and presumably mostly unknown organizations.

Method. To make the choice real, participants who had come to the lab to participate in an unrelated experiment received a 1-euro coin and a sheet with charity organizations listed in alphabetical order. Participants could choose to donate the money to one of the organizations on the list or to keep the money themselves. If they decided to make a donation they had to mark the name of the organization that the money should go to. Making no donation maintained the status quo of keeping the money and can be reasonably interpreted as no choice.

To ensure a certain degree of complexity, each organization on the list was described by its name and a list of keywords indicating its mission. The charities were sampled from the population of all 180 German organizations that complied with the standards of the German charity seal (Deutsches Spendensiegel), an association that certifies trustworthy charities. From this set, we created a large-assortment list from the 30 leading (and presumably most well known) charities according to the amount of money they collected in 2004 . To ensure that the small-assortment list would be small enough to prevent choice overload, it consisted of just the 2 biggest charity organizations. To further control for prior preferences and to test alternate set sizes, we created an additional large list that consisted of the 40 smallest (and presumably least known) charity organizations and a corresponding small list consisting of the 5 smallest organizations.

To rule out demand effects, participants made their decision anonymously. In particular, participants in the experiment were asked to open an envelope containing the instructions and list of charities and to follow the instructions in a separate booth that was set up in a corner of the lab. After completing the task (including indicating their sex and student status), participants were instructed to put the list, and the euro coin if they had made a donation, back into the envelope, seal it, and drop it into a "ballot box" within the booth. The envelopes with the different lists were mixed and indistinguishable from the outside so that the experimenter who gave out the envelopes was blind to each participant's experimental condition. At the end of the experiment, we transferred the money donated by the participants to the charities that they had indicated.

In total, 120 individuals participated in the experiment, 30 in each of the four conditions (with three sheets not filled out completely). Out of the 117 analyzed responses, there were 68 women and 49 men, and 90 of these participants $(78 \%)$ were enrolled as students.

Results. In the conditions using lists of leading charities, 28 out of 30 participants who saw the large-assortment list (30 charities) chose to donate (93\%). Of the participants who saw the small-assortment list ( 2 charities), 25 out of 30 chose to donate (83\%). With an alpha level set at 0.05 , the comparison of the two proportions revealed no statistically significant difference $[t(58)=1.2$, $p=0.235]$.

In the conditions based on the least known charities, 20 out of 28 participants who saw the large-assortment list of 40 charities chose to donate $(68 \%)$, 
while 19 out of 29 participants who saw the small-assortment list of 5 charities chose to donate (66\%). As in the previous conditions, the comparison of the two proportions revealed no statistically significant difference $[t(55)=0.18, p=$ 0.855]. If anything, in both sets of charities, participants were more likely to donate when facing the large assortment. There was a main effect of the type of charity, however, such that well-known charities received more money (88\% vs. $68 \%$ for the low-profile charities) $[t(115)=2.7, p=0.08]$.

To test whether participants simply ignored the charity organizations at the end of the list to shield themselves from having too much choice, we correlated the position of the organization on the list with the number of donations it received. A negative correlation would indicate that charities on the top of the list would have a higher probability of receiving money. Yet for both the long list with well-known charities and the long list with least-known charities, Spearman's rank correlations were virtually zero ( $r=0.03$ and $r=-0.001$, respectively), suggesting that participants looked through the whole list before selecting an option.

\section{Experiment 2b: Cultural Differences and Increasing Assortment Sizes as Moderators}

As there is no clear definition of what constitutes extensive choice, it can be assumed that the size of the assortment needed to elicit the too-much-choice effect is highly context-dependent. This makes it important to explore a wider range of assortment sizes in any given context to see if the too-much-choice effect occurs, as we do in this experiment. In addition, this experiment also tested whether the effect depends on cultural differences between Germany and the United States. So far, almost all studies that have reported an effect of too much choice were conducted in the United States. While the United States and Germany are both highly developed market democracies, it seems that people in the two countries differ in their attitude towards assortment sizes. For example, in a study by Rozin et al. (2006), the majority of Americans preferred an ice cream parlor with a large assortment of 50 different flavors over one that offered 10, while for Germans it was the other way around. Likewise, when going to a top-class restaurant, Americans were more likely than their German counterparts to expect a large choice with numerous different dishes. While it is not obvious how these different preferences influence the prevalence of the toomuch-choice effect, they reveal that there are cultural differences with regard to how people perceive assortment sizes. To further explore the potential moderating effect of cultural differences, we ran a version of the charity experiment in the United States that closely resembled the one we conducted in Germany (Experiment 2a).

Method. As in Germany, the U.S. experiment was administered following other, unrelated psychological experiments. Similar to the German version, participants received an envelope containing instructions, a list of charities, and a 1-dollar bill. Participants could either donate the dollar to one of the charities on the list or keep the money for themselves. The decision was made in private, and after completion participants dropped the sealed envelope into a box. The list of charities contained either 5, 40, or 79 different organizations.

The organizations on the list were sampled from the U.S. Web site charitynavigator.com, a non-profit organization similar to the German Charity 
Seal that lists and evaluates U.S.-based charities that have operated for at least four years, have been granted tax-exempt status, and make their accounting information publicly available. At the time we conducted the study, charity navigator.com listed a total of 204 organizations that had a national scope of work related to either animal, educational, or environmental issues. From this subset, we drew a random sample of 80 organizations, stratified by their domain of activity (27 environmental, 27 educational, and 26 animal charities). From this large sample we then drew random subsamples for the 5- and the 40-option conditions, such that the proportions of environment, educational, and animal charities were equal. Each list entry included the charity name and a onesentence description about their mission. As in the German version, the charities were listed alphabetically.

A total of 112 envelopes were administered, 36 in the 5-option condition, 37 in the 40-option condition, and 39 in the 79-option condition. Of the participants, 58 were male, 51 were female, and 3 did not indicate their gender. Participants' mean age was 20 years, ranging from 18 to 28 years.

Results. From the total number of 112 participants, 95 (85\%) decided to give to charity. Of those who made a donation, only $14(15 \%)$ indicated that they had heard of their chosen organization before, suggesting that the vast majority of participants were indeed unfamiliar with the choice set and thus could not use prior preferences.

In the 5-option condition, 29 participants (81\%) gave to charity; in the 40option condition, 32 participants $(87 \%)$ donated; and in the 79-option condition, $34(87 \%)$ gave to charity. Thus, if anything, an increase in the assortment led to more donations. In both conditions, Spearman's rank correlation between the number of donations a charity received and its position on the list was small: for 40 options, $r=0.19, p=0.100$; and for 79 options it was slightly negative $(r=-0.17, p=0.135)$, suggesting that the list position was not a reliable predictor for choosing a certain charity.

\section{Experiment 2c: Need to Justify as a Moderator}

The third experiment in this series tested whether the too-much-choice effect could be elicited when individuals must explicitly justify the choice they make. In social contexts, active choices are often more difficult to justify to others than are lack of choices or omissions (Ritov \& Barron, 1990). As a consequence, decisions may at times be avoided due to an anticipation of blame. An increasing number of choice alternatives can also increase the difficulty of justification because any decision made has to be defended against more alternatives. Furthermore, Fasolo et al. (2009) found that in real-world assortments in food markets, options are more similar to each other as the assortment size increases. This pattern could make justification of choosing a particular option from a large assortment even more difficult, because any justification based on the option's features is likely to apply to other options as well, and thus will not suffice to single out the chosen alternative. One way to avoid this difficulty would be to make no choice or to defer the choice, which would result in a too-much-choice effect.

Method. The experiment was conducted in Berlin, Germany, and its design closely resembled that of Experiments $2 \mathrm{a}$ and $2 \mathrm{~b}$. After completing an unrelated 
experiment for which they were paid, participants received an envelope with a list of charity organizations in alphabetical order and were asked if they wanted to donate 1 euro to one of the organizations on the list. If participants decided to give to charity, they had to take the euro from what they earned in the previous experiment. Participants were randomly assigned to one of three different conditions which listed either 5, 40, or 80 of the smallest-sized and presumably least-known charity organizations approved by the German Charity Seal. To implement choice justification, participants who gave to a charity were asked to write down a short statement explaining the reason why they chose this organization in particular and not another one.

A total of 119 individuals from local universities participated in the experiment-67 male, 47 female, and 5 who did not indicate their gender; $72 \%$ of all participants were students.

Results. Of the 42 participants who saw the 5-charity assortment, 37 (88\%) donated their euro. In the 40-charity condition, 28 out of 39 participants $(72 \%)$ donated, and in the 80-charity condition, 28 out of 38 participants (74\%) donated. Under the null hypothesis that no too-much-choice effect exists, the probability of finding differences of this magnitude or higher is $p=0.033(z=1.8)$ for the comparison with the 40-option condition and $p=0.05(z=1.7)$ for the comparison with the 80-option condition. Thus, for both comparisons there seems to be a small yet statistically significant $(p<0.05)$ effect of too much choice.

Omitting 12 participants across the three conditions who donated to a charity but did not write a justification, participants who donated in the 5-charity condition gave a justification for their choice that used a mean of $74(\mathrm{SD}=45)$ characters. In the 40-charity condition, the mean length was 100 characters $(\mathrm{SD}=45)$, and in the 80-charity condition it was 96 characters $(\mathrm{SD}=51)$. An analysis of variance with alpha set at 0.05 indicated a non-significant trend in the direction of greater justification length with greater assortment size $[F(2,79)=$ $2.6, p=0.08$, yet a post-hoc comparison of the small set with the two large sets indicates a statistically significant difference $[t(80)=2.3, p=0.03]$. This suggests that justifying a choice from a large assortment of 40 or 80 options requires more words and thus is presumably more difficult than justifying a choice from a small assortment of 5 options.

\section{Discussion}

The experimental design employed in all three experiments involved real choices among authentic and fairly complex options, and by the anonymizing mechanisms it effectively ruled out demand effects. With regard to the tested moderators, neither a decrease in the number of options in the small assortment (Experiment 2a) nor an increase in the large assortment (Experiments $2 \mathrm{~b}$ and 2c) elicited a too-much-choice effect. Likewise, the effect did not depend on whether the options were leading charities or unknown ones, even though overall more participants decided to give to leading charities, which suggests that the experimental manipulation itself was noticeable (Experiment 2a). Cultural or other population differences between Germany and the United States do not seem to play a moderating role either (Experiment 2b). However, even though the experimental setup was closely matched between the two countries, different charity organizations were listed in each case, which constrains 
their comparability. This problem will be addressed in our next study, described below.

Of all tested moderators, only the requirement to justify one's decision seemed to produce a too-much-choice effect. While this result stems from a comparison between experiments rather than a manipulation of need for justification within one experiment, and thus should be interpreted with caution, it fits with the assumption that justification becomes more difficult when options become more similar or otherwise more difficult to distinguish from each other, which in turn increases as assortments grow larger. This explanation gains additional support from our analysis of the number of characters used in the choice justifications, with choices from larger sets leading to longer (and hence presumably more difficult) justifications. The need for justification may thus contribute to a too-much-choice effect when it is present in a choice situation, but because it was not a variable that was manipulated in past studies, it cannot explain the differences between those previous studies that found the effect and those that found instead that more choice is better. Clearly, a more detailed picture of the processes underlying the effect of too much choice is needed. With this goal in mind, we conducted a third study, in which we could observe more aspects of both the decision processes and the decision makers themselves.

\section{THE MUSIC STUDY}

All experiments on too much choice so far have adopted a between-subjects design such that the group of individuals facing the small assortment was different from the group facing the large assortment. Such a design has certain disadvantages. For example, it could be that half of the participants show a too-much-choice effect while the other half show the reverse effect. In a betweensubjects design averaging across all participants, these differences would go unnoticed and the invalid conclusion would be drawn that there is no effect. To be able to detect such individual differences and also to detect even small effect sizes, we next employed a within-subject design in which the same participant consecutively chooses from both a small and a large assortment of classical music recordings. This setup allows for a more precise test of potential moderator variables that lie at the intersection between the structure of the assortment on the one hand and individual differences in search and choice behavior on the other hand. The main independent variables we considered included decision makers' general propensity to maximize and to regret choices made, the number of options they considered, their individual search behavior, and their degree of experience with the choice domain, all of which are explained in more detail below. In line with previous studies on choice overload, the main dependent variables of the study were the motivation to make a choice, the degree of post-choice satisfaction, and post-choice regret.

\section{Moderator Variables}

Propensity to Maximize and to Regret. According to Schwartz et al. (2002), decision makers can be classified into satisficers and maximizers. Following Simon (1955), a satisficer is described as someone who searches for something that is "good enough" and who settles with the first option that exceeds a 
predetermined level of aspiration. Maximizers, on the other hand, aim for the best within a given set of options, and hence will search through all those options to find it (Foxall \& James, 2003). To measure individuals' propensity to maximize, Schwartz et al. developed a 13 -item scale that includes statements such as "I never settle for second best," "When shopping, I have a hard time finding clothes that I really like," and "Renting videos is really difficult. I'm always struggling to pick the best one"- the more an individual agrees with such statements, the greater their rated tendency to maximize.

Schwartz et al. conjectured that the too-much-choice effect would be more likely for maximizers because their goal of finding the best option becomes more difficult to achieve and involves more effort as the number of options increases. At the same time, the second-best, not-chosen option in larger assortments will be more similar to the chosen option, which implies relatively higher opportunity costs, which could lead to a decrease in satisfaction and the motivation to choose. Schwartz et al. further proposed that the effect of too much choice is governed by decision makers' propensity to regret their decisions (e.g., focusing on forgone opportunities and options), a personality trait that has been found to be relatively stable across situations.

In support of the idea that the propensity to maximize moderates the toomuch-choice effect, Haynes and Olson (2007) found that individuals who described themselves as maximizers experienced more difficulties and more frustration with the decision process when the choice set they faced increased from 3 to 10, whereas the experience of satisficers did not change as much. Furthermore, in a study on job search, Iyengar, Wells, and Schwartz (2006) found that senior college students who were classified as maximizers made a greater effort to search for job offers and were able to get better-paid jobs after graduation than did satisficers, but they ended up being less satisfied with their choices.

Consideration Set Size. A necessary precondition of the too-much-choice effect is that decision makers actually take the additional options in the large assortment into account. Past research on human decision behavior found that individuals making choices often apply a two-stage process in which they first screen options to form a consideration set from which they then choose (Paulssen \& Bagozzi, 2005; Hauser \& Wernerfelt, 1990; Reilly, 1985; White \& Hoffrage, 2009). Given such a process, what ultimately matters is not the total number of options available but rather the number of options that are seriously considered for the final decision. If so, it can be conjectured that the effect of too much choice is mediated by the size of that consideration set rather than the size of the assortment per se, and assessing consideration set size might help to explain previous divergent findings.

Search Behavior. The three factors of propensity to maximize, propensity to regret one's decisions once they are made, and consideration set size all tap into subjective experiences measured by self-reports. To further validate these concepts on behavioral grounds, we also assessed decision makers' search behavior prior to choice. For example, in line with Iyengar, Wells, and Schwartz's (2006) study on job search, maximizers would be expected to prolong their search in the face of a large assortment. Likewise, a consideration set can only be as large as the number of options that have been inspected. 
Expertise, Option Attractiveness, Difficulty, and Cultural Differences. Following up on the restaurant study and the charity studies, we also examined individuals' domain-specific expertise, their perceived attractiveness of the assortment, and their experienced choice difficulty when making a choice. The reasons for assessing these variables were similar to those already outlined in the previous studies: To the degree that people are knowledgeable about the assortment, information processing becomes easier, specific point preferences become more likely, and the too-much-choice effect less likely. Based on previous research on choice overload that mostly used rather appealing options, it can also be conjectured that the effect is more likely to occur for assortments that are perceived as attractive. Finally, measuring decision makers' difficulty with the choice process further enables us to compare our experiment to previous studies.

To test for cultural differences as a moderator, we ran this experiment in Germany and the United States. Because classical music is similarly enjoyed across many cultures, exactly the same choice sets could be used in both countries, which allowed for a more precise comparison between them.

\section{Method}

To test the influence of all these variables in a within-subject design, we had each participant make choices of classical music albums from two different music assortments displayed on a computer screen. The options consisted of recently released CDs of classical music from the record label Deutsche Grammophon, an internationally renowned label that specializes in high-quality recordings of classical music. We compiled two large assortments of $30 \mathrm{CDs}$ each from the most recent releases of Deutsche Grammophon: one set with vocal music and one set with orchestral music. From each of these two large assortments, we then randomly selected a subset with $6 \mathrm{CDs}$. Thus, there were four different assortments of CDs that can be described based on two orthogonal factors: music style (orchestral vs. vocal) and assortment size (small vs. large). Each participant saw and made choices from two of these four assortments.

Potential order effects were controlled for by having half the participants first choose from a small assortment followed by a large assortment; the other half first chose from a large assortment followed by a small assortment. To motivate participants to make choices from both sets, each person saw one assortment consisting of classical orchestral music and the other of classical vocal music. The order in which participants saw the two types of music was counterbalanced with the order of the assortment size, which resulted in four different experimental groups. To get familiar with the experimental setting, all participants first chose a CD from a "training set" of 14 CDs of Deutsche Grammophon piano recordings.

The CD assortments were displayed on a 17-inch computer screen as a collection of thumbnail images $(36 \times 36$ pixels each) that showed the miniaturized pictures of the CD covers in a random order. The last name of the composer and the abbreviated CD title were displayed underneath each thumbnail. A detailed description of each $\mathrm{CD}$ could be retrieved by clicking on the thumbnails with the left mouse button. The detailed description consisted of a full-size picture of the cover, the full CD title, and the full names of the composer, the conductor, the orchestra, and the choir (for vocal music only). Participants could freely browse 
through all of the recordings in each assortment they saw, and whenever they were done with this they were asked to then choose one CD from that assortment. After making each choice, they heard the first two minutes of the first track on the chosen album.

In Germany, the experiment was conducted at the Max Planck Institute for Human Development in Berlin, and in the United States at Indiana University in Bloomington. As compensation for their participation, participants in Berlin received 8 euros (approximately $\$ 10$ ) and participants in Bloomington received course credit.

Dependent Variables. Post-choice satisfaction and post-choice regret were assessed based on multiple questionnaire items immediately after participants had listened to each sound sample. All items called for answers on a 9-point Likert scale ranging from -4 (lowest rating) to +4 (highest rating), with textual anchors on both sides of the scale (see Appendix for a list of all items). Choice motivation was assessed at the end of the experiment by asking participants how much they were willing to pay for the orchestral and for the vocal CD that they had previously selected (the covers of both of which were displayed again to remind participants of their choices): Higher willingness to pay indicates greater choice motivation. To make this task meaningful, participants were informed that the three people willing to pay the most for their chosen CD in each category would be allowed to buy the respective CD at the price they stated, a procedure commonly referred to as a sealed-bid first-price auction or discriminatory auction. To give people a sense of the actual market values, they were informed that the CDs on display cost on average about 20 euros or 20 dollars, respectively.

Moderator and Control Variables. After listening to the sound sample following each CD choice, participants rated the attractiveness of the assortment and answered three questions assessing their perceived choice difficulty (again on a 9-point scale). Participants were then asked to rate the assortment's complexity as well as to indicate how much they deliberated before choosing. To assess the size of participants' consideration set, we also asked participants to state the number of options they short-listed. As a measure of regret, participants were further asked how many of the non-chosen CDs might have been better than the one they selected. The number of CDs that were looked up in detail and the total decision time were recorded as behavioral measures of the individual search process. Because personality traits that relate to decision making have been shown to be often context dependent (Beattie et al., 1994; Hanoch, Johnson, \& Wilke, 2006), we also included a domain-specific measure of maximizing in this task by asking participants to rate how much they were trying to select the best piece of music from the current assortment.

After finishing the full computer-based choice task, participants filled out a paper-and-pencil questionnaire that assessed their prior preferences and domainspecific expertise on classical music based on six items. The questionnaire also measured perceived attractiveness of the different types of classical music as well as the general propensity to maximize and to regret, based on the scales by Schwartz et al. (2002) and its respective German version (Greifeneder \& Betsch, 2006). As control variables, participants rated how motivated they were to participate in the study and how carefully they had answered the questions. 
Participants. In Berlin, 80 students from local universities participated in the study (20 in each condition). Of these participants, $49 \%$ were female; the average age was 26 years ( $\mathrm{SD}=2.9$ years). In Bloomington, 87 undergraduate students from Indiana University participated. Of these participants, $69 \%$ were female, and the average age was 20 years $(\mathrm{SD}=1.6$ years $)$.

\section{Results}

Control Variables. Participants in both countries were motivated to participate in the study and all reported that they carefully answered the questions. There was no statistically significant $(\alpha=0.05)$ difference between the four experimental presentation-order groups in either country on any of the three main dependent variables (post-choice satisfaction, post-choice regret, and willingness to pay), so the data were collapsed across the order of music style (orchestral first or vocal first) and the order of assortment size (small set first or large set first), separately within each country. To allow for a more concise summary in the following paragraphs, results from the Berlin sample will be immediately followed by results from the Bloomington sample, in parentheses.

\section{Main Effect of Assortment Size on Attractiveness, Complexity, and} Consideration Set Size. When compared within participants, 55\% (45\%) rated the 30-CD set as more attractive than the 6-CD set; thus, the assortments were perceived overall as similarly attractive. Of all participants, $83 \%(62 \%)$ perceived the large choice set as more complex than the small set and 65\% (47\%) rated the choice from the small set as easier than the choice from the large set.

On average, participants' reported consideration set size was $2.6, \mathrm{SD}=1.2$ $(3.4, \mathrm{SD}=2.1)$ in the small assortment and 5.3, $\mathrm{SD}=4.0(8.0, \mathrm{SD}=8.1)$ in the large assortment. Of all participants, 80\% (71\%) formed larger consideration sets for the large assortment compared to the small assortment. Thus, for the majority of participants, enlarging the assortment led to an increase in the consideration set size and in the perceived assortment complexity. However, the number of considered options in the large set is still small, suggesting that participants successfully shielded themselves from the excess.

Main Effect of Assortment Size on Search Behavior. On average, participants looked up details on $5, \mathrm{SD}=1.6(5, \mathrm{SD}=1.4)$ different $\mathrm{CDs}$ in the small assortment and 16, $\mathrm{SD}=11.2(14, \mathrm{SD}=11.3)$ different CDs in the large assortment. Within participants, $74 \%$ (68\%) looked up more options in the large set than in the small set. While the absolute number of options looked up is higher in the large set, the relative proportion of explored options was notably smaller in the large assortment (around 50\%, compared to around 84\% in the small assortment).

In the small assortment, it took an average $^{1}$ of $29, \mathrm{SD}=18$ seconds $(24$, $\mathrm{SD}=17$ seconds) from the moment the assortment was displayed on the screen until the final choice of one particular piece of music. In the large set, this search and exploration phase took an average of $64, \mathrm{SD}=54$ seconds $(44, \mathrm{SD}=36 \mathrm{sec}-$ onds). Of all participants, $79 \%$ (77\%) took longer to choose from the large set compared to the small set. When choosing from the small assortment, participants

1 Following the recommendation of Wilcox (1998), mean statistics on decision times are 20\% trimmed to control for outliers, which means that the $10 \%$ largest and the $10 \%$ smallest observations are not included in these analyses. 
spent $5.4, \mathrm{SD}=2.7$ seconds $(4.7, \mathrm{SD}=3.0$ seconds $)$ on average to examine the details of one option before they went on to the next or terminated their search. In the large assortment, the mean time to examine a single option was $5.1, \mathrm{SD}=$ 3.1 seconds (4.0, $\mathrm{SD}=3.3$ seconds). Aside from the option examination times, the other measures indicate that the search process differed depending on the number of options to choose from.

Effect of Assortment Size on the Main Dependent Variables. Cronbach's $\alpha$ for the 6-item post-choice satisfaction scale is 0.98 (0.98) for both the small and the large assortment. For the 3 -item post-choice regret scale, Cronbach's $\alpha=0.79(0.80)$ for the small assortment and $0.86(0.83)$ for the large assortment. These values indicate good reliability for both scales in both countries (Bortz \& Döring, 2002). Of all participants, 54\% (51\%) were more or equally satisfied with the chosen option from the large set, $51 \%$ (52\%) experienced less or equal regret after choosing from the large set, and 64\% (68\%) were willing to pay more for an option selected from the large set, indicating that overall there was no main effect of too much choice in terms of any of the main dependent variables.

\section{Influence of Moderator Variables on the Main Dependent Vari-} ables. Because the data indicate considerable inter-individual differences in the three main dependent variables (satisfaction, regret, and willingness to pay), a too-much-choice effect could have occurred for at least some participants. In line with this, these three variables are highly correlated with each other (Cronbach's $\alpha=0.87$ in Berlin and $\alpha=0.83$ in Bloomington), indicating that a person who is satisfied with his or her choice also regrets the choice less and is willing to pay more for it, and vice versa for dissatisfied individuals. In total, there were 26 (20) participants who experienced the choice from the small set as more satisfactory and less regrettable and were willing to pay more for a CD chosen from the small assortment, and there were 28 (30) participants who showed the reverse pattern on all three dependent variables. The remaining participants could not be categorized unequivocally.

In order to test whether these individual differences can be explained by any of the moderator variables included in this study, for each participant we calculated an overall "overload score" by summing up the differences between small and large set on each of the three dependent variables, normalized based on its respective standard deviation. A positive overall value indicates overload or a too-much-choice effect at the individual level, while a negative value indicates that more choice is perceived positively. Next, we calculated Pearson correlations between the overload score and the potential moderator variables to see if any of these potential moderator variables could explain the variation in the overload score. The mean overload score was $0.84, \mathrm{SD}=3.83(0.28, \mathrm{SD}=3.21)$.

Maximizing and Regret as Moderators. In Berlin $(r=0.13)$ as well as in Bloomington $(r=0.02)$, the overload score did not correlate with participants' general propensity to maximize, measured based on the Schwartz et al. (2002) scale. The same holds for participants' propensity to regret $(r=0.14$ in Berlin and $r=0.11$ in Bloomington). One reason that the assessed personality traits provide little explanation could be that their reliability is rather low: Cronbach's $\alpha$ for the maximization scale is $\alpha=0.62(0.70)$ and for the regret scale it is 
$\alpha=0.76$ (0.62). These low reliabilities make it difficult to interpret the personality construct underlying these scales, a problem that previous studies also faced (Haynes \& Olson, 2007; Iyengar, Wells, \& Schwartz, 2006).

As outlined above, the tendency to maximize might be domain specific, which is why we asked participants after each choice to specify to what extent they were trying to select the best music CD in the assortment. Yet in the Berlin sample this domain-specific measure does not explain overload either $(r=0.07$ in the small set and $r=-0.08$ in the large set). In the Bloomington sample, there is a weak correlation for the domain-specific maximizing in the small set $(r=0.34)$ but not in the large set $(r=-0.11)$. There is also only a small correlation between the general maximization scale scores and the domain-specific tendency to maximize in the small set ( $r=0.14$ in Berlin and $r=0.26$ in Bloomington) and in the large set ( $r=0.14$ in Berlin and $r=0.26$ in Bloomington), which further questions the validity of a general maximization trait in the present context.

Expertise as a Moderator. In both countries, the six items assessing prior preferences and expertise were highly intercorrelated, with Cronbach's $\alpha=0.81$ (0.89). Thus, for subsequent analyses we collapsed the items into an aggregated score for each participant. Despite the good reliability of the measure, the degree of domain-specific expertise did not explain the variation in the overload measure ( $r=0.11$ in Berlin and $r=-0.10$ in Bloomington). This is in contrast to the findings of Mogilner, Rudnick, and Iyengar (2008), who found a too-much-choice effect for individuals with little knowledge and experience but not for experienced participants.

Search Process, Consideration Size, and Choice Difficulty as Moderators. The number of options that were looked up prior to choice did not predict overload either. For the number of options looked up in the small set, the correlations are $r=-0.1(0.01)$. For the large set, the correlations are $r=0.12$ (0.03). The same holds true for the time spent searching. Here, the correlations are $r=-0.13(0.13)$ for the small set and $r=0.11(0.02)$ in the large set. In Berlin as well as in Bloomington, overload was independent of the size of the consideration sets in the small set $(r=-0.13$ and $r=-0.09)$ and in the large set $(r=0.15$ and $r=-0.04)$.

In the Berlin sample, those participants who were more overloaded experienced choosing from the small set as easier $(r=-0.41)$; however, this relation does not hold for the Bloomington sample $(r=-0.01)$ and it does not hold for choosing from the large set either ( $r=0.2$ for Berlin and $r=0.16$ for Bloomington). This suggests that experiencing a choice as difficult does not moderate the too-much-choice effect either.

Perception of the Assortment as a Moderator. In both countries, overload correlated with participants perceiving a higher number of better, nonchosen options in the rest of the assortment: $r=-0.34(-0.53)$ for the small assortment and $r=0.51$ (0.37) for the large. This suggests that the more overloaded participants were, the more they thought that they chose a relatively good option from the small set and a relatively poor option from the large set. Along the same lines, overload correlated with the perceived attractiveness of the assortment. A more attractive small set corresponded to more overload $(r=0.42$ and $r=0.24)$ and so did a less attractive large set $(r=-0.14$ and $r=-0.30)$. Yet the correlations between overload and both number of better 
options and perceived assortment attractiveness might be due to the similar theoretical underpinnings of the two latter variables: The perceived number of better yet forgone options clearly is an aspect of regret (McConnell et al., 2000), while the attractiveness of the assortment might be influenced by the satisfaction with the chosen option. Thus, while these differences affirm the results found with the dependent variables, they add little to their explanation.

\section{Discussion}

Overall, there was no main effect of too much choice on any of the three main dependent variables, namely, post-choice satisfaction, post-choice regret, and choice motivation (i.e., willingness to pay). Yet the strong correlation between these three dependent variables and the inter-individual variance with regard to these variables suggests that a too-much-choice effect might have occurred for about a quarter of the participants within each country (the overloaded group). However, despite the fact that participants carefully answered the questions and were motivated to participate in the experiment, this inter-individual variation could not be explained by any of the numerous moderators we assessed: The effect seems not to depend on cultural differences, the amount of search, the size of the consideration set, the propensity to maximize or to avoid regret, domain-specific expertise, the overall attractiveness of the assortment, nor the difficulty of the decision. Thus, it could be that the individual differences in the three main dependent variables are due to random variation and that by chance some participants had high scores on all three dependent variables. Alternatively, it can be speculated that more than one precondition is necessary to reliably elicit a too-much-choice effect. Yet the more preconditions that have to be met for it to occur, the lower the generalizability and robustness of the effect, and hence ultimately also the smaller its importance.

\section{GENERAL DISCUSSION}

According to the too-much-choice effect, an increase in the number of options decreases the motivation to make a choice and/or the satisfaction with the finally chosen option. Past research has provided some evidence in favor of this effect, yet so far, little is known about its boundary conditions, let alone its underlying psychological mechanisms. In a series of three studies we aimed to fill in this picture by investigating the conditions under which a too-much-choice effect could occur. The tested moderator variables came from consideration of the choice environment, the individual decision maker, and the interaction between the two. In the first study (restaurants) we tested whether the effect depends on the attractiveness of the small assortment compared to the large assortment, and on the perceived rather than the objective assortment sizes. In the second series of experiments (charities), we explored a wider set of assortment sizes, controlled for prior preferences, tested for cultural differences, and introduced the need to justify one's decision. In the third study (music), we adopted a within-subject design that allowed us to test the moderating role of personality traits including maximizing and regret, along with other factors, including search behavior and subjective experience of choice difficulty, in both Germany and the United States.

Despite this wide range of moderators and choice contexts, we found no toomuch-choice effect in Germany or the United States except when individuals 
needed to justify their choice (charity study, Experiment 2c). Nor did we find an interaction of the effect with any of the tested moderators. Together, these results allow for the conclusion that the too-much-choice effect is less robust than previously thought. The fact that other researchers found the effect further emphasizes the need for a theory of too much choice that covers these divergent findings. Based on our results, it can be hypothesized that the effect depends on multiple boundary conditions or an interaction between several factors that all have to hold before the effect can be elicited. To study such interactions in more detail, a paradigm is needed in which the effect of too much choice reliably occurs. We next discuss other variables that may be important in such a paradigm and indicate how they will lead to testable predictions for future research.

\section{Assortment Structure}

In an extension of the debate on information overload, researchers found that the perception of variety is not just a function of the number of options or attributes but also depends on structural factors such as the (dis)organization of the assortment, the number and distribution of attribute levels, the correlation between attributes, and the similarity between options (Fasolo et al., 2006; Gopinath \& Glassman, 2008; Hoch, Bradlow, \& Wansink, 1999; Kahn \& Lehmann, 1991; Kahn \& Wansink, 2004; Lee \& Lee, 2004; Lurie, 2002, 2004; van Herpen \& Pieters, 2002). Other researchers found that beyond just influencing perception, these structural aspects also affect the ease with which relevant information can be retrieved, which in turn affects the quality of the decision (Lee \& Lee, 2004) and the motivation to make a choice (Gourville \& Soman, 2005; Russo, 1977). With regard to the too-much-choice effect, the similarity between different options and the degree to which different aspects need to be traded off against each other might also be of importance because these aspects have been shown to effect satisfaction, deliberation time, and choice probability (Chernev, 2005; Dhar, 1997; Dhar \& Nowlis, 1999; Fasolo, Carmeci, \& Misuraca, 2009; Fasolo, McClelland, \& Todd, 2007; Hsee \& Leclerc, 1998; Redelmeier \& Shafir, 1995). Past research on too much choice, including our own experiments, has not controlled for these specific aspects of the structure of an assortment, some of which could help explain the diverging results, so future research should take these factors into account. However, if conflict between options were a sufficient precondition, the too-much-choice effect should be widespread, because many choice sets in the real world contain conflict-inducing trade-offs characterized by negative correlations between some attribute values-for instance, quality and price (Curry \& Riesz, 1988; Gerstner, 1985; Monroe, 1973).

\section{Decision Strategy}

Besides the structure of the assortment, whether a choice is difficult or not also depends on the applied decision strategy (Fasolo et al., 2009; Hu, Huhmann, \& Hyman 2007; Kozup \& Creyer, 2006; Shanteau \& Thomas, 2000; Strebel, O’Donnell, \& Myers, 2004; White \& Hoffrage, 2009; Jessup et al., 2009). The importance of decision strategies and individual differences in their use has been emphasized by research on adaptive decision making. According to this line of research, individuals are capable of reasonable choices even when the number of options and the amount of information about them grow large (Gigerenzer, Todd, \& ABC Research Group, 1999; Payne, Bettman, \& Johnson, 
1992). From this tradition, the too-much-choice effect could be interpreted as a failure to adapt one's decision strategy to the current situation. If individuals do not have a strategy to handle the situation they face, deferring (or abandoning) the choice might be more likely. While the measurement of search strategies and the propensity to maximize in our music study was a first step toward a better understanding of the underlying decision processes, a more detailed analysis should help to further reveal the degree to which strategy use moderates the effect of too much choice.

\section{Decision Avoidance}

According to Anderson (2003), making no choice (which is the main dependent variable within the too-much-choice literature) is not a well-defined dependent variable in itself, but rather an umbrella term that embraces different phenomena requiring different explanations. Making no choice can be due to a preference for having no change or maintaining the status quo (Johnson \& Goldstein, 2004; Ritov \& Baron, 1990, 1992). Also, no choice will be made (now) if the decision maker procrastinates-for instance, in order to search for more information (Tversky \& Shafir, 1992). In this case, a choice might be made at a later point in time; however, once delayed, many things never get done (Ariely \& Wertenbroch, 2002). These types of no-choice require that alternative options are recognized as such and that the possibility of making a choice is at least considered. In that sense, not choosing can be seen as the result of a more or less deliberate decision process that could be consistent with a decision maker's intentions (White \& Hoffrage, 2009). But no choice can also be made if the possibility of choice as well as the alternative options are not even considered in the first place, for example, if individuals do not realize that they can switch to another service provider or if they do not bother to identify any alternatives to choose among. In that case, not choosing does not result from a decision process but from the lack thereof. With regard to studies on too much choice, it is important to clarify what people are actually doing if they do not make a choice, as the reasons for no choice could differ significantly depending on the situation. The different ways of making no choice also have important implications for cognitive models of the too-much-choice effect (Jessup et al., 2009). To get a better understanding of the effect, future studies need to be more explicit in their definition of the dependent variable.

\section{CONCLUSION}

There is a discrepancy between the growing number of publications that report a demotivating effect of too much choice on the one hand and empirical data showing the opposite effect or no effect on the other hand. Clearly, this discrepancy calls out for a sound theory that predicts when and why the too-much-choice effect will occur. Our studies are intended to help build the base of such a theory by exploring the boundary conditions of the effect. The fact that most of the variables that we tested were not sufficient to elicit choice overload suggests that the too-muchchoice effect is less robust than previously thought. Certainly, much research lies ahead in order to understand the conditions in which the effect may be reliably manifested. But whatever a satisfactory theory of the effect of too much choice will eventually look like, it must be based on consideration of the structure of the 
assortments and the choice environment more broadly, the choice strategies used by individual decision makers, and the interaction between the two.

\section{REFERENCES}

Anderson, C. J. (2003). The psychology of doing nothing: Forms of decision avoidance result from reason and emotion. Psychological Bulletin, 129, 139-166.

Ariely, D., \& Wertenbroch, K. (2002). Procrastination, deadlines, and performance: Selfcontrol by precommitment. Psychological Science, 13, 219-224.

Arnold, S. J., Oum, T. H., \& Tigert, D. J. (1983). Determinant attributes in retail patronage: Seasonal, temporal, regional, and international comparisons. Journal of Marketing Research, 20, 149-157.

Beattie, J., Baron, J., Hershey, J. C., \& Spranca, M. D. (1994). Psychological determinants of decision attitude. Journal of Behavioral Decision Making, 7, 129-144.

Bortz, J., \& Döring, N. (2002). Forschungsmethoden und Evaluation für Human- und Sozialwissenschaftler. Heidelberg: Springer.

Botti, S., \& Iyengar, S. S. (2006). The dark side of choice: When choice impairs social welfare. Journal of Public Policy and Marketing, 25, 24-38.

Broniarczyk, S. M., Hoyer, W. D., \& McAlister, L. (1998). Consumers' perceptions of the assortment offered in a grocery category: The impact of item reduction. Journal of Marketing Research, 35, 166-176.

Brown, N. J., Read D., \& Summers, B. (2003). The lure of choice. Journal of Behavioral Decision Making, 16, 297-308.

Chase, W. G., \& Simon, H. A. (1973). Perception in chess. Cognitive Psychology, 4, 55-81.

Chernev, A. (2003a). Product assortment and individual decision processes. Journal of Personality and Social Psychology, 85, 151-162.

Chernev, A. (2003b). When more is less and less is more: The role of ideal point availability and assortment in consumer choice. Journal of Consumer Research, 30, 170-183.

Chernev, A. (2005). Feature complementarity and assortment in choice. Journal of Consumer Research, 31, 748-759.

Craig, C. S., Gosh, A., \& McLafferty, S. (1984). Models of the retail location process: A review. Journal of Retailing, 60, 5-36.

Curry, D., \& Riesz, P. (1988). Prices and price-quality relationships: A longitudinal analysis. Journal of Marketing, 52, 36-51.

Dhar, R. (1997). Consumer preference for a no-choice option. Journal of Consumer Research, 24, 215-231.

Dhar, R., \& Nowlis, S. M. (1999). The effect of time pressure on consumer choice deferral. Journal of Consumer Research, 25, 369-384.

Fasolo, B., Carmeci, F. A., \& Misuraca, R. (2009). The effect of choice complexity on perception of time spent choosing: When choice takes longer but feels shorter. Psychology \& Marketing, 26, 213-228.

Fasolo, B., Hertwig, R., Huber, M., \& Ludwig, M. (2009). Size, entropy, and density: What is the difference that makes the difference between small and large real-world assortments? Psychology \& Marketing, 26, 254-279.

Fasolo, B., McClelland, G. H., \& Todd, P. M. (2007). Escaping the tyranny of choice: When fewer attributes make choice easier. Marketing Theory, 7, 13-26.

Fasolo, B., Misuraca, R., McClelland, G. H., \& Cardaci, M. (2006). Animation attracts: The attraction effect in an on-line shopping environment. Psychology \& Marketing, 23, 799-811.

Foxall, G. R., \& James, V. K. (2003). The behavioral ecology of brand choice: How and what do consumers maximize? Psychology \& Marketing, 20, 811-836.

Gerstner, E. (1985). Do higher prices signal higher quality? Journal of Marketing Research, $22,209-215$.

Gigerenzer, G., Todd, P. M., \& ABC Research Group. (1999). Simple heuristics that make us smart. New York: Oxford University Press. 
Gopinath, M., \& Glassman, M. (2008). The effect of language product descriptions on product evaluations. Psychology \& Marketing, 25, 233--261.

Gourville, J. T., \& Soman, D. (2005). Overchoice and assortment type: When and why variety backfires. Marketing Science, 24, 382-395.

Greifeneder, R., \& Betsch, C. (2006). Validation and German translation of the maximizing scale. Zeitschrift für Sozialpsychologie, 37, 233-243.

Hanoch, Y., Johnson, J. G., \& Wilke, A. (2006). Domain-specificity in experimental measures and participant recruitment: An application to risk-taking behavior. Psychological Science, 17, 300-304.

Hauser, J. R., \& Wernerfelt, B. (1990). An evaluation cost model of consideration sets. Journal of Consumer Research, 16, 393-408.

Haynes, G. A. (2009). Testing the boundaries of the choice overload phenomenon: The effect of number of options and time pressure on decision difficulty and satisfaction. Psychology \& Marketing, 26, 204-212.

Haynes, G. A., \& Olson, J. M. (2007). You choose, you lose? The effect of too many attractive alternatives on choice difficulty, post-decisional satisfaction, and regret. Poster presented at the 8th Annual Meeting of the Society for Personality and Social Psychology, Memphis, TN.

Hoch, S. J., Bradlow, E. T., \& Wansink, B. (1999). The variety of an assortment. Marketing Science, 18, 527-546.

Hsee, C. K., \& Leclerc, F. (1998). Will products look more attractive when presented separately or together. Journal of Consumer Research, 25, 175-186.

Hu, J., Huhmann, B. A., \& Hyman, M. R. (2007). The relationship between task complexity and information search: The role of self-efficiancy. Psychology \& Marketing, 24, 253-270.

Huffman, C., \& Kahn, B. E. (1998). Variety for sale: Mass customization or mass confusion? Journal of Retailing, 74, 491-513.

Hutchinson, J. M. C. (2005). Is more choice always desirable? Evidence and arguments from leks, food selection, and environmental enrichment. Biological Reviews, 80, 73-92.

Iyengar, S. S., \& Lepper, M. R. (2000). When choice is demotivating: Can one desire too much of a good thing? Journal of Personality and Social Psychology, 79, 995-1006.

Iyengar, S. S., Jiang, W., \& Huberman, G. (2004). How much choice is too much: Determinants of individual contributions in $401(\mathrm{k})$ retirement plans. In O. S. Mitchell \& S. Utkus (Eds.), Pension design and structure: New lessons from behavioral finance (pp. 83-95). Oxford: Oxford University Press.

Iyengar, S. S., Wells, R. E., \& Schwartz, B. (2006). Doing better but feeling worse: Looking for the "best" job undermines satisfaction. Psychological Science, 17, 143-150.

Jessup, R. K., Veinott, E. S., Todd, P. M., \& Busemeyer, J. R. (2009). Leaving the store empty-handed: Testing explanations for the too-much-choice effect using decision field theory. Psychology \& Marketing, 26, 299-320.

Johnson, E. J. \& Goldstein, D. G. (2003). Do defaults save lives? Science, 302, 1338-1339.

Kahn, B. E. (1995). Consumer variety-seeking among goods and services. An integrative review. Journal of Retailing and Consumer Services, 2, 139-148.

Kahn, B. E., \& Lehmann, D. R. (1991). Modeling choice among assortments. Journal of Retailing, 67, 274-299.

Kahn, B. E., \& Wansink, B. (2004). The influence of assortment structure on perceived variety and consumption quantities. Journal of Consumer Research, 30, 519-533.

Koelemeijer, K., \& Oppewal, H. (1999). Assessing the effects of assortment and ambience: A choice experimental approach. Journal of Retailing, 75, 319-345.

Kozup, J. C., \& Creyer, E. H. (2006). Boundary conditions of the impact of a hypervigliant coping style on the subjective decision-making experience. Psychology \& Marketing, 23, 905-925.

Lee, B. K., \& Lee, W. N. (2004). The effect of information overload on consumer choice quality in an on-line environment. Psychology \& Marketing, 21, 159-183.

Lurie, N. H. (2002). Decision making in information-rich environments: The role of information structure. Advances in Consumer Research, 29, 91-92. 
Lurie, N. H. (2004). Decision making in information-rich environments: The role of information structure. Journal of Consumer Research, 30, 473-486.

Mazursky, D., \& Jacoby, J. (1986). Exploring the development of store images. Journal of Retailing, 62, 145-165.

McConnell, A. R., Niedermeier, K. E., Leibold, J. M., El-Alayli, A. G., Chin, P. P., \& Kuiper, N. M. (2000). What if I find it cheaper someplace else? Role of prefactual thinking and anticipated regret in consumer choice. Psychology \& Marketing, 17, 281-298.

Mogilner, C., Rudnick, T., \& Iyengar, S. S. (2008). The mere categorization effect: How the presence of categories increases choosers' perceptions of assortment variety and outcome satisfaction. Journal of Consumer Research, 35, 202-215.

Monroe, K. B. (1973). Buyer's subjective perceptions of price. Journal of Marketing Research, 10, 70-80.

Paulssen, M., \& Bagozzi, R. P. (2005). A self-regulatory model of consideration set formation. Psychology \& Marketing, 22, 785-812.

Payne, J. W., Bettman, J. R., \& Johnson, E. J. (1992). Behavioral decision research: A constructive processing perspective. Annual Review of Psychology, 43, 87-131.

Redelmeier, D. A., \& Shafir, E. (1995). Medical decision making in situations that offer multiple alternatives. Journal of the American Medical Association, 273, 302-305.

Reilly, M. (1985). Individual and product correlates of evoked set size for consumer package goods. Advances in Consumer Research, 12, 492-496.

Reutskaja, E., \& Hogarth, R. M. (2009). Satisfaction in choice as a function of the number of alternatives: When "goods satiate." Psychology \& Marketing, 26, 197-203.

Ritov, I., \& Baron, J. (1990). Reluctance to vaccinate: omission bias and ambiguity. Journal of Behavioral Decision Making, 3, 263-277.

Ritov, I., \& Baron, J. (1992). Status-quo and omission bias. Journal of Risk and Uncertainty, 5, 49-61.

Rozin, P., Fischler, C., Shields, C., \& Masson, E. (2006). Attitudes towards large numbers of choices in the food domain: A cross-cultural study of five countries in Europe and the USA. Appetite, 46, 304-308.

Russo, J. E. (1977) The value of unit price information. Journal of Marketing Research, $14,193-201$.

Schwartz, B. (2004). The paradox of choice: Why more is less. New York: Harper Collins.

Schwartz, B., Ward, A., Monterosso, J., Lyubomirsky, S., White, K., \& Lehman, D. (2002). Maximizing versus satisficing: Happiness is a matter of choice. Journal of Personality and Social Psychology, 83, 1178-1197.

Shah, A. M., \& Wolford, G. (2007). Buying behavior as a function of parametric variation of number of choices. Psychological Science, 18, 369-370.

Shanteau, J., \& Thomas, R. P. (2000). Fast and frugal heuristics: What about unfriendly environments? Behavioral and Brain Sciences, 23, 762-763.

Simon, H. A. (1955). A behavioral model of rational choice. Quarterly Journal of Economics, 69, 99-118.

Strebel, J., O’Donnell, K., \& Myers, J. G. (2004). Exploring the connection between frustration and consumer choice behavior in a dynamic decision environment. Psychology \& Marketing, 21, 1059-1076.

Tversky, A., \& Shafir, E. (1992). Choice under conflict: The dynamics of deferred decision. Psychological Science, 3, 358-361.

van Herpen, E., \& Pieters, R. (2002). The variety of an assortment: An extension to the attribute-based approach. Marketing Science, 21, 331-341.

White, C. M., \& Hoffrage, U. (2009). Testing the tyranny of too much choice against the allure of more choice. Psychology \& Marketing, 26, 280-298.

Wilcox, R. R. (1998). How many discoveries have been lost by ignoring modern statistical methods. American Psychologist, 53, 300-314.

Correspondence regarding this article should be sent to: Benjamin Scheibehenne, Cognitive Science Program, Indiana University-Bloomington, 1101 E. 10th Street, Bloomington, IN 47405 (bscheibe@indiana.edu). 


\section{APPENDIX}

\section{List of Items Used in the Music Study}

\begin{tabular}{lcc}
\hline Dependent Variables Assessed after Each Choice & Lower & Upper \\
Anchor $(-4)$ & Anchor (+4) \\
\hline
\end{tabular}

Post-Choice Satisfaction (6 items)

In comparison with all pieces of [orchestra/vocal] music on display, how satisfied are you with the piece you chose?

In comparison with all pieces of [orchestra/vocal] music of the "Deutsche Grammophon" label, how satisfied are you with the piece you chose?

In comparison with all pieces of [orchestra/vocal] music that you know, how satisfied are you with the piece you chose?

Did you like the piece of [orchestra/vocal] music that you just listened to?

Did you enjoy listening to the piece of [orchestra/vocal] music that you chose?

Overall, how satisfied are you with the piece of music [orchestra/vocal] that you just listened to?

Post-Choice Regret (3 items)

Do you regret your choice?

Do you think that a different piece of [orchestra/vocal] music from that assortment would have been better than the one you chose?

If you could repeat the choice, would you choose the same piece of [orchestra/vocal] music again?

$\begin{array}{ll}\begin{array}{l}\text { not at all } \\ \text { satisfied }\end{array} & \text { very satisfied } \\ \text { not at all } & \\ \text { satisfied } & \text { very satisfied } \\ \text { not at all } & \\ \text { satisfied } & \text { very satisfied } \\ \text { did not like } & \begin{array}{l}\text { liked it very } \\ \text { much }\end{array} \\ \text { it at all } & \text { enjoyed it } \\ \text { did not enjoy } & \text { very much } \\ \text { it at all } & \text { very satisfied } \\ \text { not at all } & \\ \text { satisfied } & \\ & \text { very much } \\ \text { no regret } & \text { regret } \\ \text { at all } & \text { probably yes } \\ \text { rather not } & \end{array}$

rather not probably yes

\begin{tabular}{lcc}
\hline Moderator Variables Assessed after Each Choice & Lower & Upper \\
Anchor $(-4)$ & Anchor $(+4)$ \\
\hline
\end{tabular}

Perceived Choice Difficulty (3 items)

How hard/easy was it for you to make a choice?

\begin{tabular}{|c|c|}
\hline very easy & very hard \\
\hline $\begin{array}{l}\text { not at all } \\
\text { exhausting }\end{array}$ & $\begin{array}{l}\text { very } \\
\text { exhaustin }\end{array}$ \\
\hline $\begin{array}{l}\text { not at all } \\
\text { frustrating }\end{array}$ & $\begin{array}{l}\text { very } \\
\text { frustratir }\end{array}$ \\
\hline $\begin{array}{l}\text { did not try } \\
\text { at all }\end{array}$ & $\begin{array}{l}\text { tried very } \\
\text { much }\end{array}$ \\
\hline $\begin{array}{l}\text { did not try } \\
\text { at all }\end{array}$ & $\begin{array}{l}\text { tried very } \\
\text { much }\end{array}$ \\
\hline
\end{tabular}

How exhausting was it for you to choose a piece of [orchestra/vocal] music?

Did you experience the choice process as frustrating?

Domain-Specific Maximizing (2 items)

Did you try to choose a "good" piece of [orchestra/vocal] music from the assortment?

Did you try to choose "the best" piece of [orchestra/vocal] music from the assortment? 
Domain-Specific Regret (3 items)

Do you regret your choice?

$\begin{array}{ll}\text { no regret } & \text { very much } \\ \text { at all } & \text { regret } \\ \text { rather not } & \text { probably yes }\end{array}$

Do you think that a different piece of [orchestra/vocal] music from that assortment would have been better than the one you chose?

If you could repeat the choice, would you choose the same piece of vocal music again?

rather not probably yes

\section{Other Items}

How much did you deliberate about your choice?

very little very high deliberation deliberation

How many CDs did you short-list?

In your opinion, how many of the music CDs above would have been better than the one you selected?

In your opinion, how attractive was the assortment?

not at all

very attractive

In your opinion, how complex was this assortment?

attractive

very complex

not at all complex

\begin{tabular}{lcc}
\hline Moderator Items at the End of the Experiment & Lower & Upper \\
Anchor (1) & Anchor (9)
\end{tabular}

Prior Preferences and Domain-Specific Expertise (6 items)

In general, how much do you like to listen to orchestra music?

don't like it

like it very

In general, how often do you listen to orchestra music?

at all

much

never daily

How knowledgeable are you about orchestra music?

don't know know a whole anything lot

In general, how much do you like to listen to vocal music?

don't like

it at all

like it very

much

In general, how often do you listen to vocal music?

never

daily

How knowledgeable are you about vocal music?

don't know

know a whole anything lot

\section{Perceived Attractiveness of the Different Types of Classical Music (6 items)}

Orchestra music

Chamber music

Piano music

Vocal music

Choral music

Opera/theater

$\begin{array}{ll}\text { don't like it } & \text { like it very } \\ \text { at all } & \text { much } \\ \text { don't like it } & \text { like it very } \\ \text { at all } & \text { much } \\ \text { don't like it } & \text { like it very } \\ \text { at all } & \text { much } \\ \text { don't like it } & \text { like it very } \\ \text { at all } & \text { much } \\ \text { don't like it } & \text { like it very } \\ \text { at all } & \text { much } \\ \text { don't like it } & \text { like it very } \\ \text { at all } & \text { much }\end{array}$

